\title{
Blade Design Optimisation for Fixed-Pitch Fixed-Speed Wind Turbines
}

\author{
Lin Wang, Xinzi Tang, and Xiongwei Liu \\ Wind Energy Engineering Research Group, School of Computing, Engineering and Physical Sciences, \\ University of Central Lancashire, Preston PR1 2HE, UK \\ Correspondence should be addressed to Xiongwei Liu, xliu9@uclan.ac.uk
}

Received 7 April 2012; Accepted 4 July 2012

Academic Editors: A. Bosio, B. S. Hyun, and Z. A. Zainal

Copyright ( 2012 Lin Wang et al. This is an open access article distributed under the Creative Commons Attribution License, which permits unrestricted use, distribution, and reproduction in any medium, provided the original work is properly cited.

Fixed-pitch fixed-speed (FPFS) wind turbines have some distinct advantages over other topologies for small wind turbines, particularly for low wind speed sites. The blade design of FPFS wind turbines is fundamentally different to fixed-pitch variablespeed wind turbine blade design. Theoretically, it is difficult to obtain a global mathematical solution for the blade design optimisation. Through case studies of a given baseline wind turbine and its blade airfoil, this paper aims to demonstrate a practical method for optimum blade design of FPFS small wind turbines. The optimum blade design is based on the aerodynamic characteristics of the airfoil, that is, the lift and drag coefficients, and the annual mean wind speed. The design parameters for the blade optimisation include design wind speed, design tip speed ratio, and design attack angle. A series of design case studies using various design parameters are investigated for the wind turbine blade design. The design outcomes are analyzed and compared to each other against power performance of the rotor and annual energy production. The design outcomes from the limited design cases demonstrate clearly which blade design provides the best performance. This approach can be used for any practice of FPFS wind turbine blade design and refurbishment.

\section{Introduction}

Wind energy has been receiving more and more attention as one of the most viable renewable energy sources. Wind turbine technologies have been developed to achieve better performance for harvesting the energy in the wind in the last two decades. One of the major R\&D areas for wind turbine technology development is blade design optimisation [1].

For small- and medium-size wind turbines, fixed-pitch or stall-regulated horizontal-axis wind turbine is one of the two common topologies in both research and industrial sectors, and the other one is pitch-controlled wind turbine [2].

For fixed-pitch wind turbines, there are two different rotor speed control strategies, that is, fixed speed and variable speed $[2,3]$.

Due to the nature of fixed-speed control, a fixed-pitch fixed-speed (FPFS) wind turbine uses asynchronous or induction generator with gearbox connected to the rotor, and the generator can be directly tied to the grid [2].
Because of the unique advantage of direct grid connection using asynchronous generators, even though with relative lower rotor power coefficient $C_{\mathrm{PR}}$ than its variable-speed version at wind speed away from design wind speed, there are still much interest in both research and industrial sectors in developing efficient wind turbines of the type [4-6].

It is obvious that the rotor design of fixed-speed wind turbines differs from variable-speed wind turbines. There are a few questions to ask so as to determine an optimal rotor or blade design. What is the optimal design wind speed given the rated power of the wind turbine and wind resources, that is, annual mean wind speed? What is the optimal rotor speed for the wind turbine? What is the best attack angle for the blade design given the blade airfoil and its aerodynamic characteristics?

Compared to variable-speed wind turbines which use complicated converters for grid connection, fixed-speed wind turbines have the advantageous of being simple, robust, and reliable, well proven and of low cost [5]. Venkatesh 
and Kulkarni's research work demonstrated that with high values of Weibulls shape parameter, FPFS wind turbines are fairly competitive in terms of annual energy production (AEP), which is about $88 \%$ of its variable-speed version [6]. Therefore, they are used widely in small and medium wind energy market [7].

Blade aerodynamic design and analysis is the first step to achieve the expected power performance. The blade design parameters include airfoil shape, design attack angle, design tip speed ratio, and rated wind speed, which are to be considered in the wind turbine blade aerodynamic design stage. The selection of these blade parameters is often based on blade element momentum (BEM) theory [8].

Further blade design optimisation is essential to achieve a better power performance. Previous research indicates that wind turbine blade design optimisation has been carried out based on BEM theory, generally in an iterative way [9]. Bak's research work on the sensitivity of key parameters in wind turbine blade design on power performance demonstrated that the design tip speed ratio should be between 5.5 and 8.5 depending on the airfoil performance [10].

Researchers have been trying to use advanced computational fluid dynamics (CFD) methods for wind turbine blade design optimisation. For example, CFD was used by Thumthae and Chitsomboon to calculate the optimal attack angles so as to achieve maximum power outputs for an untwisted horizontal axis wind turbine blade [11] This is partly due to the flows passing through and around the rotating blades tending to interact, which can only be modelled in $3 \mathrm{D}$ flow domain. The other reason is that $2 \mathrm{D}$ aerodynamic data from wind tunnel testing are generally not available at high attack angles. At a high attack angle, the flow around the airfoil starts to separate, which leads to stall. 3D CFD aerodynamic models have been therefore developed with the aim to obtain a detailed 3D flow but have not yet become a well-accepted engineering tool due to uncertainties [12]. It remains a challenge to predict the stall accurately, which is typical for FPFS wind turbines under high winds or high attack angles. The aerodynamic behaviours of rotating wind turbine blades at high attack angles have not been fully understood.

Modern artificial intelligence (AI) control algorithms are also used in wind turbine blade design optimisation. For example, artificial neural networks were also presented to estimate the optimal tip speed ratio for wind turbines $[13,14]$. However, the AI optimization methods are dealing with individual design parameters, which are intertwined and should be considered simultaneously. There is a need to address the selection principles of these parameters before executing blade design codes and evaluate the impacts of these parameters on the annual energy production (AEP).

This paper aims to demonstrate a practical method for the blade design optimisation for FPFS wind turbines through a $10 \mathrm{~kW}$ wind turbine blade design case study using airfoil DU93W210 based on maximum AEP for low wind speed sites and, in particular, to highlight the importance of selection of the design wind speed, design tip speed ratio, and design airfoil attack angle for the optimum blade design.
In this paper, we put together different design cases of the wind turbine blade and we use the Schmitz rotor theory [8] to estimate the shape of blades. Then, we use GHBladed [15] to calculate the performance of these blades. The modelling of rotor aerodynamics provided by GH-Bladed is based on the blade element momentum (BEM) theory [8]. The criterion for the optimisation used in this paper is the highest AEP based on a particular wind speed Weibulls distribution.

This paper is structured in the following way. For a comprehensive understanding of the methodology, we briefly summarize the AEP calculation in Section 2. The baseline wind turbine is then introduced in Section 3. The design parameters are discussed in Section 4. Section 5 details the case studies with findings. Section 6 concludes the paper with recommendations.

\section{Annual Energy Production Calculation [16]}

2.1. Wind Turbine Generator Power. The power output of a wind turbine generator can be expressed as

$$
P=\frac{1}{2} \eta C_{\mathrm{PR}} \rho A v^{3}
$$

where $\eta$ is the transmission efficiency of the wind turbine, including both mechanical and electrical efficiency, $C_{\mathrm{PR}}$ is the rotor power coefficient of the wind turbine, $C_{P}=\eta C_{\mathrm{PR}}$ is the power coefficient of the wind turbine, $\rho$ is the air density, $A=\pi R^{2}$ is the rotor swept area, and $v$ is the wind velocity.

2.2. Wind Speed Weibulls Distribution. The wind power density is given by

$$
p_{w}=\frac{1}{2} \rho v^{3} .
$$

The annual mean wind power density can be expressed as

$$
\bar{p}_{w}=\frac{1}{2} \rho \times \frac{1}{8760} \times \int_{\text {year }} v^{3} d t .
$$

Considering the natural wind speed frequency distribution throughout the year, that is, Weibulls distribution:

$$
f_{\text {Weibulls }}(v)=\frac{k}{a}\left(\frac{v}{a}\right)^{k-1} \exp \left(-\left(\frac{v}{a}\right)^{k}\right),
$$

where $k$ is the shape parameter and $a$ is the scale parameter, which depends on the wind resource of the site. The characteristics of wind resources differ from site to site.

Then, we have the annual mean wind power density:

$$
\bar{P}_{w}=\frac{1}{2} \rho v^{3} f_{\text {Weibulls }}(v)
$$

If the shape parameter is unknown, the calculation of the AEP for a wind turbine should be based on Rayleigh distribution, which assumes a shape parameter of $k=2$ in Weibulls distribution:

$$
f_{\text {Rayleigh }}(v)=\frac{\pi}{2} \frac{v}{\bar{v}^{2}} \exp \left(-\frac{\pi}{4} \frac{v^{2}}{\bar{v}^{2}}\right) .
$$


TABle 1: Basic design parameters of the base-line $10 \mathrm{~kW}$ at $9 \mathrm{~m} / \mathrm{s}$ wind turbine.

\begin{tabular}{lc}
\hline Generator rated power output $P_{r}$ & $10000 \mathrm{~W}$ \\
Transmission efficiency $\eta$ & $0.85 \%$ \\
Wind turbine rated rotor power $P_{\text {rotor }}$ & $11765 \mathrm{~W}$ \\
Number of blades $B$ & 3 \\
Rotor diameter & $9.0 \mathrm{~m}$ \\
\hline
\end{tabular}

Here, $\bar{v}$ is the annual mean wind speed (AMWS):

$$
\bar{v}=\frac{1}{8760} \int_{0}^{\infty} f_{\text {Weibulls }}(v) d v
$$

2.3. Annual Energy Production. The AEP for a wind turbine for a specific site can be expressed as

$$
E=8760 \times \frac{1}{2} \eta \rho A \int_{\text {cut in }}^{\text {cut out }} v^{3} C_{\mathrm{PR}}(v) \times f_{\text {Rayleigh }}(v) d v,
$$

where $C_{\mathrm{PR}}(v)$ is the rotor power coefficient of the wind turbine, which is a complex function of the wind speed (or tip speed ratio) for a fixed-pitch fixed-speed wind turbine.

\section{Baseline Wind Turbine}

Let us start from the baseline $10 \mathrm{~kW}$ at $9 \mathrm{~m} / \mathrm{s}$ fixed-pitch fixed-speed wind turbine with a 4-pole asynchronous generator. The basic parameters of the wind turbine are listed in Table 1.

\section{Design Parameters}

4.1. Rotor Speed. Due to noise issue for small- and mediumsize wind turbines, which are generally installed close to properties, the wind turbine blade tip speed should not exceed $70 \mathrm{~m} / \mathrm{s}$.

For variable-speed machines, a high blade tip speed, such as between $65 \mathrm{~m} / \mathrm{s}$ and $70 \mathrm{~m} / \mathrm{s}$, is normally considered, so as to achieve high rotor power coefficient $C_{\mathrm{PR}}$ and wind turbine power performance [10]. However, for fixed-speed machines, we should address the blade tip speed carefully.

Consider the operation wind speed from $3 \mathrm{~m} / \mathrm{s}$ to $20 \mathrm{~m} / \mathrm{s}$ and define the blade tip speed $68 \mathrm{~m} / \mathrm{s}$, then the tip speed ratio $\lambda$ in the operation wind speed range varies from 22.667 to 3.4. This basically means at low wind speed, such as at $5 \mathrm{~m} / \mathrm{s}$, $\lambda=13.6$, the rotor power coefficient $C_{\mathrm{PR}}$ will be very low [8]. If we define blade tip speed $40 \mathrm{~m} / \mathrm{s}$, then the tip speed ratio $\lambda$ in the operation wind speed range varies from 13.333 to 2 . Then at wind speed $5 \mathrm{~m} / \mathrm{s}, \lambda=8$, which is likely to exhibit much better performance for sites with low annual mean wind speed.

Therefore, let us first consider three blade tip speeds $40 \mathrm{~m} / \mathrm{s}, 50 \mathrm{~m} / \mathrm{s}$, and $60 \mathrm{~m} / \mathrm{s}$, which correspond to rotor speeds $84.883 \mathrm{rpm}, 106.103 \mathrm{rpm}$, and $127.324 \mathrm{rpm}$, respectively.

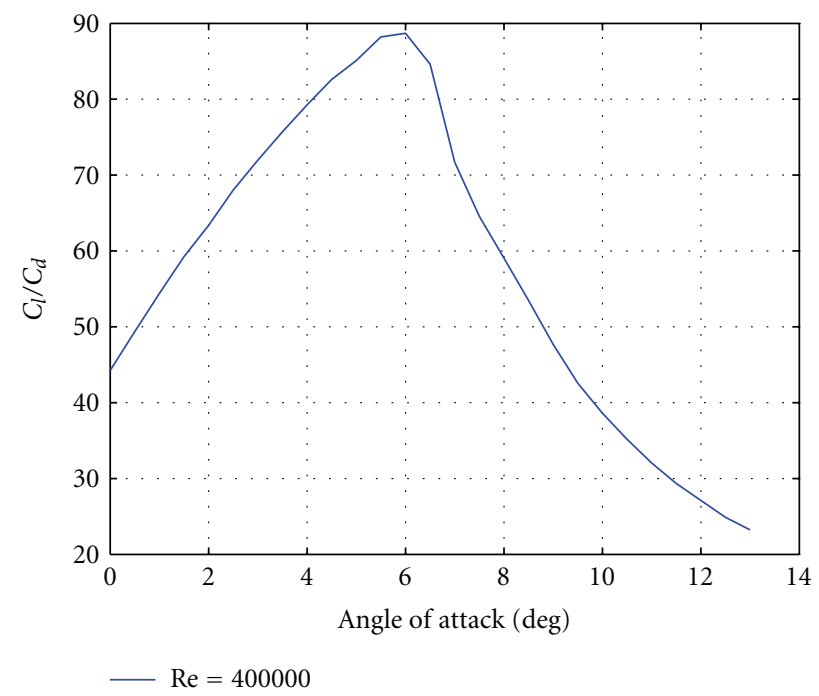

Figure 1: Lift/drag ratio of airfoil DU93W210 at $\mathrm{Re}=400,000$.

4.2. Airfoil and Design Attack Angle. The airfoil used for the baseline wind turbine is DU93W210. The airfoil performance is affected by Reynolds number, which is defined by [8]:

$$
\operatorname{Re}=\frac{\rho U L}{\mu},
$$

where, in terms of wind turbine airfoil, $\rho$ is the air density, $\mu$ is the air viscosity, $U$ is the relative wind velocity, and $L$ is the chord length of the airfoil.

Generally, the Reynolds number of each blade section is not exactly the same. By means of estimation using the method provided by Singh et al. [17], the Reynolds number of each blade section is between $3 \times 10^{5}-5 \times 10^{5}$ for this wind type turbine. To simplify the design process, we choose the Reynolds number $4 \times 10^{5}$ as the design Reynolds number. The aerodynamic performance of DU93W210 airfoil at different Reynolds numbers can be calculated using XFoil software, which is widely used to design and analyze airfoils [18]. Figure 1 depicts the lift/drag ratio of the airfoil against the interested attack angles from 0 to $13^{\circ}$.

The maximum lift/drag ratio is $C_{l} / C_{d}=88.72$ at attack angle $\alpha_{0}=6.0^{\circ}$.

For the design cases, we offset one design attack angle on both side of the attack angle $\alpha_{0}=6.0^{\circ}$ with maximum lift/drag ratio, with a step of $0.5^{\circ}$ in between, and the three design attack angles are $\alpha_{0}=5.5^{\circ}, \alpha_{0}=6.0^{\circ}$, and $\alpha_{0}=6.5^{\circ}$. Table 2 lists their $C_{l}, C_{d}$, and $C_{l} / C_{d}$.

4.3. Design Wind Speed and Rated Wind Speed. Different to variable-speed machines, there are two sets of wind speed we should consider for fixed-speed machine, that is, maximum power coefficient wind speed and rated wind speed $V_{\text {rated }}$. We call the former the design wind speed $V_{\text {design }}$, which means at this wind speed, the rotor power coefficient $C_{\mathrm{PR}}$ achieves 
TABLE 2: Design attack angles and aerodynamics characteristics of DU93W210 airfoil.

\begin{tabular}{lccc}
\hline$\alpha_{0}\left(^{\circ}\right)$ & $C_{l}$ & $C_{d}$ & $C_{l} / C_{d}$ \\
\hline 5.5 & 1.129 & 0.0128 & 88.20 \\
6.0 & 1.180 & 0.0133 & 88.72 \\
6.5 & 1.219 & 0.0144 & 84.65 \\
\hline
\end{tabular}

TABle 3: Design tip speed ratio $\lambda_{0}$ for the chosen blade tip speeds and design wind speeds.

\begin{tabular}{lccc}
\hline & $40 \mathrm{~m} / \mathrm{s}$ & $50 \mathrm{~m} / \mathrm{s}$ & $60 \mathrm{~m} / \mathrm{s}$ \\
\hline $5.5 \mathrm{~m} / \mathrm{s}$ & 7.273 & 9.091 & 10.909 \\
$6.5 \mathrm{~m} / \mathrm{s}$ & 6.154 & 7.692 & 9.231 \\
$7.5 \mathrm{~m} / \mathrm{s}$ & 5.333 & 6.667 & 8 \\
$8.0 \mathrm{~m} / \mathrm{s}$ & 5 & 6.25 & 7.5 \\
$8.5 \mathrm{~m} / \mathrm{s}$ & 4.706 & 5.882 & 7.059 \\
$9.0 \mathrm{~m} / \mathrm{s}$ & 4.444 & 5.556 & 6.667 \\
\hline
\end{tabular}

TABle 4: Design blade tip speed.

\begin{tabular}{lcccccc}
\hline & $\lambda_{0}=5$ & $\lambda_{0}=6$ & $\lambda_{0}=7$ & $\lambda_{0}=8$ & $\lambda_{0}=9$ & $\lambda_{0}=10$ \\
\hline $5.5 \mathrm{~m} / \mathrm{s}$ & & & 38.5 & 44 & 49.5 & 55 \\
$6.5 \mathrm{~m} / \mathrm{s}$ & & 39 & 45.5 & 52 & 58.5 & 65 \\
$7.5 \mathrm{~m} / \mathrm{s}$ & 37.5 & 45 & 52.5 & 60 & 67.5 & \\
$8.0 \mathrm{~m} / \mathrm{s}$ & 40 & 48 & 56 & 64 & & \\
$8.5 \mathrm{~m} / \mathrm{s}$ & 42.5 & 51 & 59.5 & 68 & & \\
$9.0 \mathrm{~m} / \mathrm{s}$ & 45 & 54 & 63 & & & \\
\hline
\end{tabular}

its maximum value. At the rated wind speed $V_{\text {rated }}$, the rotor power achieves its nominal power output.

In terms of the Rayleigh distribution of wind speed, wind turbine blade design should try to focus on the best power performance at prevailing wind speed range. For sites with low wind speed, the prevailing wind speed varies between $4 \mathrm{~m} / \mathrm{s}$ and $8 \mathrm{~m} / \mathrm{s}$.

Therefore, let us consider the design wind speeds $V_{\text {design }}$ at $5.5 \mathrm{~m} / \mathrm{s}, 6.5 \mathrm{~m} / \mathrm{s}, 7.5 \mathrm{~m} / \mathrm{s}, 8.0 \mathrm{~m} / \mathrm{s}, 8.5 \mathrm{~m} / \mathrm{s}$, and $9.0 \mathrm{~m} / \mathrm{s}$.

Then, we have the design tip speed ratio $\lambda_{0}$ in terms of the blade tip speeds in Section 4.2, which are listed in Table 3.

Now we have 18 different blade tip speed ratios listed in Table 3. Obviously there is no point to consider all of them. Let us choose $5,6,7,8,9$, and 10 as the design tip speed ratio $\lambda_{0}$ for the design cases, then we have 18 combinations of design cases with three attack angles (as listed in Table 2).

For the operation, let us consider the combinations of tip speeds listed in Table 4.

Take the example of $\lambda_{0}=5$, at design wind speed $7.5 \mathrm{~m} / \mathrm{s}$, the tip speed is $37.5 \mathrm{~m} / \mathrm{s}$, there are three design cases with $\alpha_{0}=5.5^{\circ}, \alpha_{0}=6.0^{\circ}$, and $\alpha_{0}=6.5^{\circ}$, respectively.

During the design exercise, we should make sure that the maximum rotor power output does not exceed $11,765 \mathrm{~W}^{*} 120 \%=14,118 \mathrm{~W}$. We are designing a $10 \mathrm{~kW}$ wind turbine, the maximum overloading to the generator is $120 \%$, and we should rule out any case with maximum rotor power output over 14,118 W. Otherwise, we are not talking about $10 \mathrm{~kW}$ wind turbine. Additionally, with this approach, the

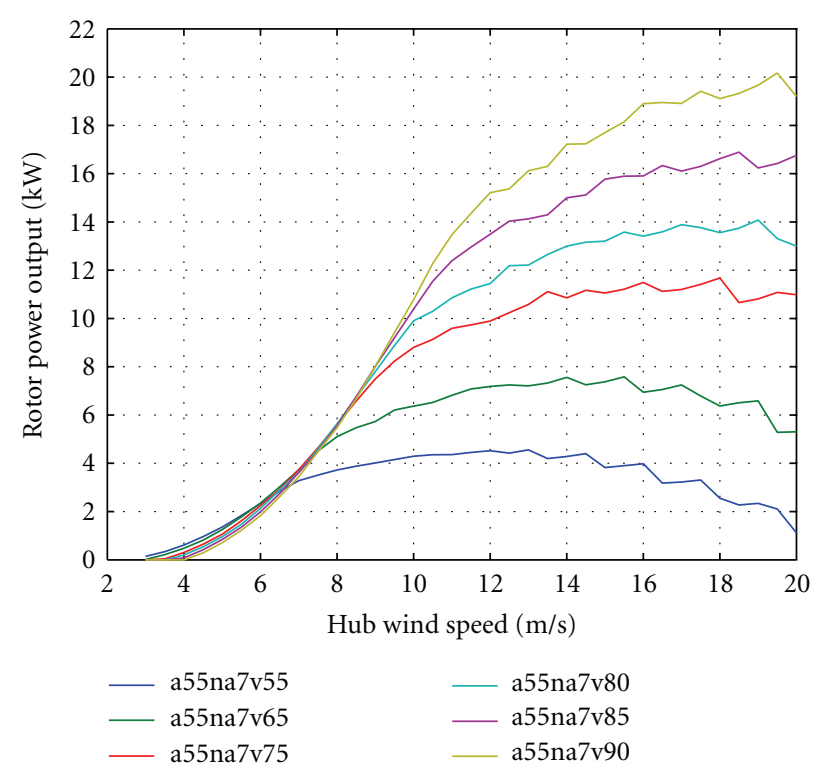

FIgURE 2: Rotor power output based on $\alpha_{0}=5.5^{\circ}$ and $\lambda_{0}=7$.

rated wind speeds will result from further calculation and analysis.

\section{Design Case Studies}

5.1. With Different Design Wind Speeds. Let us first consider design attack angle $\alpha_{0}=5.5^{\circ}$ and design tip speed ratio $\lambda_{0}=7$. Using $\mathrm{GH}$-Bladed we can calculate the rotor power for design wind speed $V_{\text {design }}=5.5 \mathrm{~m} / \mathrm{s}, 6.5 \mathrm{~m} / \mathrm{s}, 7.5 \mathrm{~m} / \mathrm{s}$, $8 \mathrm{~m} / \mathrm{s}$, and $9 \mathrm{~m} / \mathrm{s}$, respectively, as depicted in Figure 2 .

In Figure 2, for the expression " $\mathrm{a}^{* * *} \mathrm{na}^{*} \mathrm{v}^{* *}$ ”, “a” represents attack angle, a55 means $\alpha_{0}=5.5^{\circ}$; "na" represents design tip speed ratio, na7 means $\lambda_{0}=7$; "v" represents design wind speed, v55 means $V_{\text {design }}=5.5 \mathrm{~m} / \mathrm{s}$.

Figure 2 reveals that design wind speed $V_{\text {design }}=5.5 \mathrm{~m} / \mathrm{s}$ and $V_{\text {design }}=6.5 \mathrm{~m} / \mathrm{s}$ are too low for the wind turbine because the wind turbine rotor cannot achieve expected rotor power output 11,765 W for the whole operation wind speed range. Also, when the design wind speed is above $8.5 \mathrm{~m} / \mathrm{s}$, the rotor power output exceeds the rated power too much and therefore is not a valid design as well. We should only consider design wind speed between $7.5-8 \mathrm{~m} / \mathrm{s}$.

Figure 2 also reveals that with higher design wind speed, the rotor exhibits higher power output when the wind speed is higher than about $8 \mathrm{~m} / \mathrm{s}$; however, the rotor exhibits lower power output when the wind speed is lower than about $8 \mathrm{~m} / \mathrm{s}$. Figure 3 enlarges the figure section for the wind speed between $3-8 \mathrm{~m} / \mathrm{s}$. This figure also indicates that higher design wind speed means higher cut-in wind speed.

Figure 4 shows the annual energy production (AEP) for annual mean wind speed (AMWS) from $3.5 \mathrm{~m} / \mathrm{s}$ to $8 \mathrm{~m} / \mathrm{s}$, and Figure 5 enlarges the figure section for AMWS between 3.5$4.5 \mathrm{~m} / \mathrm{s}$.

Figures 4 and 5 reveal that with higher than $4.5 \mathrm{~m} / \mathrm{s}$ AMWS, higher design wind speed exhibits higher AEP. 


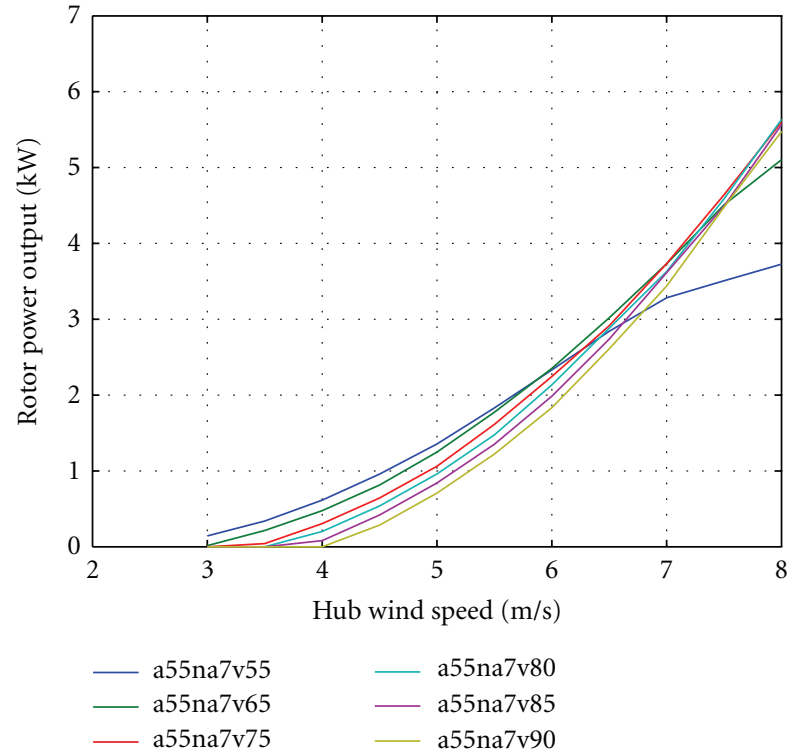

FIGURE 3: Rotor power output based on $\alpha_{0}=5.5^{\circ}$ and $\lambda_{0}=7$ for wind speed between $3-8 \mathrm{~m} / \mathrm{s}$.

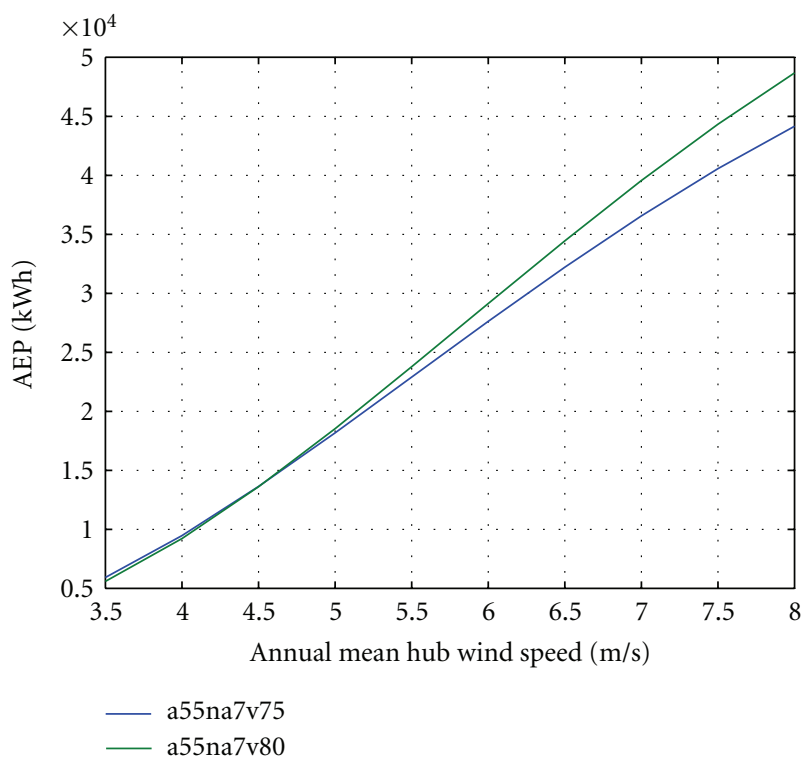

FIGURe 4: AEP based on $\alpha_{0}=5.5^{\circ}$ and $\lambda_{0}=7$ for AMWS between $3.5-8 \mathrm{~m} / \mathrm{s}$.

However when the AWMS is less than $4.5 \mathrm{~m} / \mathrm{s}$, things are different. Generally when the AMWS is less than $4.5 \mathrm{~m} / \mathrm{s}$, wind energy project should not be considered. Therefore, we can conclude here that design wind speed $8 \mathrm{~m} / \mathrm{s}$ exhibits better power performance than design wind speed $7.5 \mathrm{~m} / \mathrm{s}$.

5.2. With Different Design Attack Angles. Now let us consider different design attack angles by keeping design wind speed $V_{\text {design }}=8 \mathrm{~m} / \mathrm{s}$ and design tip speed ratio $\lambda_{0}=7$. Figure 6 depicts the rotor power performances of this set of design cases.

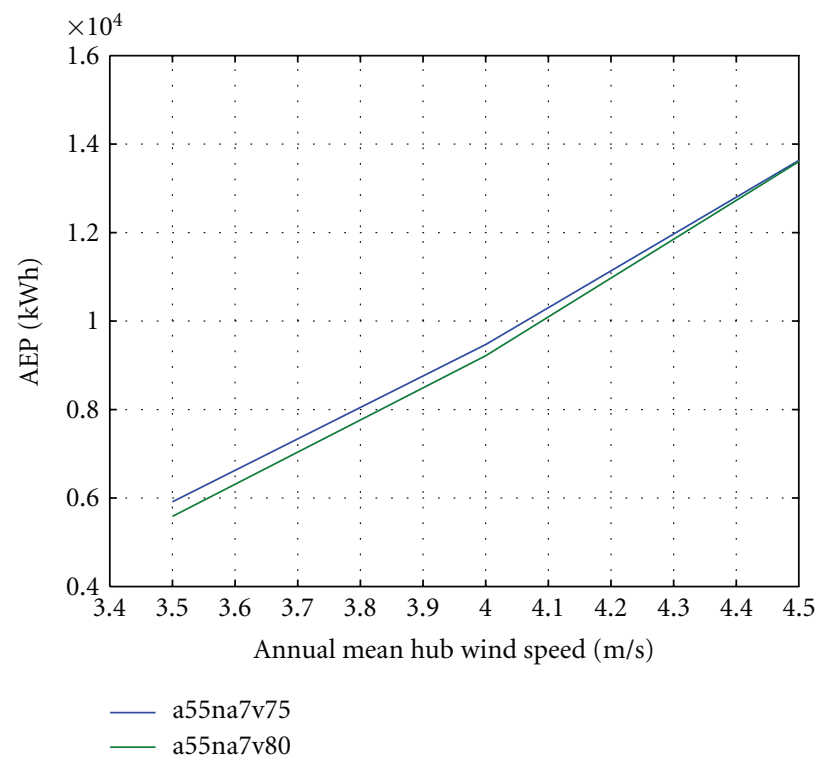

FIGURE 5: AEP based on $\alpha_{0}=5.5^{\circ}$ and $\lambda_{0}=7$ for AMWS between $3.5-4.5 \mathrm{~m} / \mathrm{s}$.

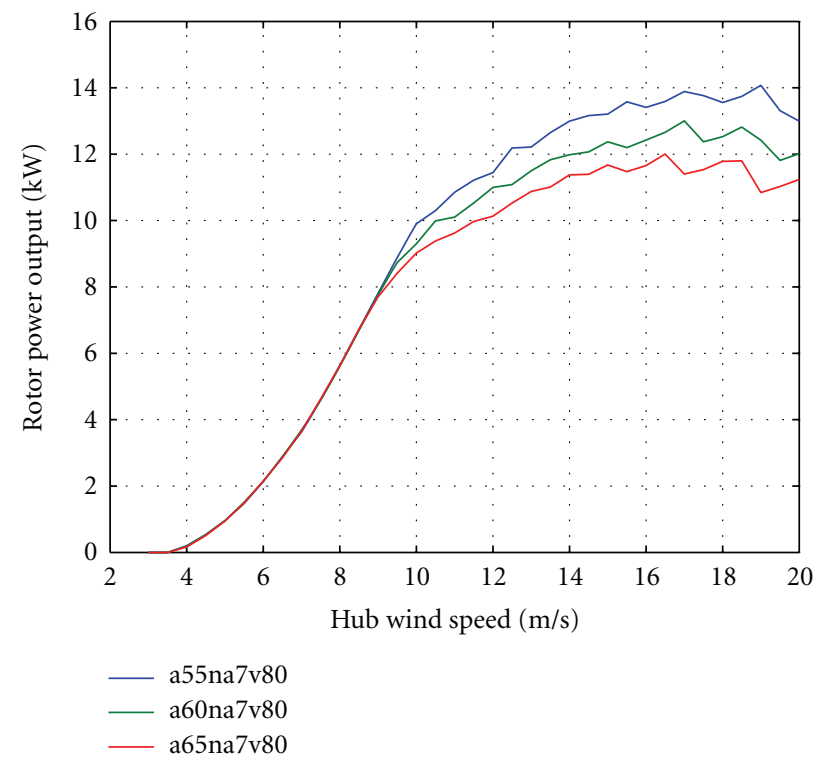

FIGURE 6: Rotor power output based on $V_{\text {design }}=8 \mathrm{~m} / \mathrm{s}$ and $\lambda_{0}=7$.

Similar to Figure 2, in Figure 6, for the expression

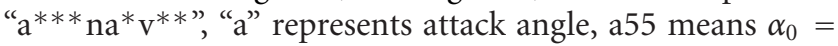
$5.5^{\circ}$; “na” represents design tip speed ratio, na7 means $\lambda_{0}=$ 7 ; "v" represents design wind speed, v80 means $V_{\text {design }}=$ $8.0 \mathrm{~m} / \mathrm{s}$.

Figure 7 shows the annual energy production (AEP) for annual mean wind speed (AMWS) from $3.5 \mathrm{~m} / \mathrm{s}$ to $8 \mathrm{~m} / \mathrm{s}$.

Figures 6 and 7 demonstrate that $\alpha_{0}=5.5^{\circ}$ exhibits better power performance than $\alpha_{0}=6.0^{\circ}$ and $\alpha_{0}=6.5^{\circ}$, even though the maximum lift/drag ratio appears at attack angle $\alpha_{0}=6.0^{\circ}$. 


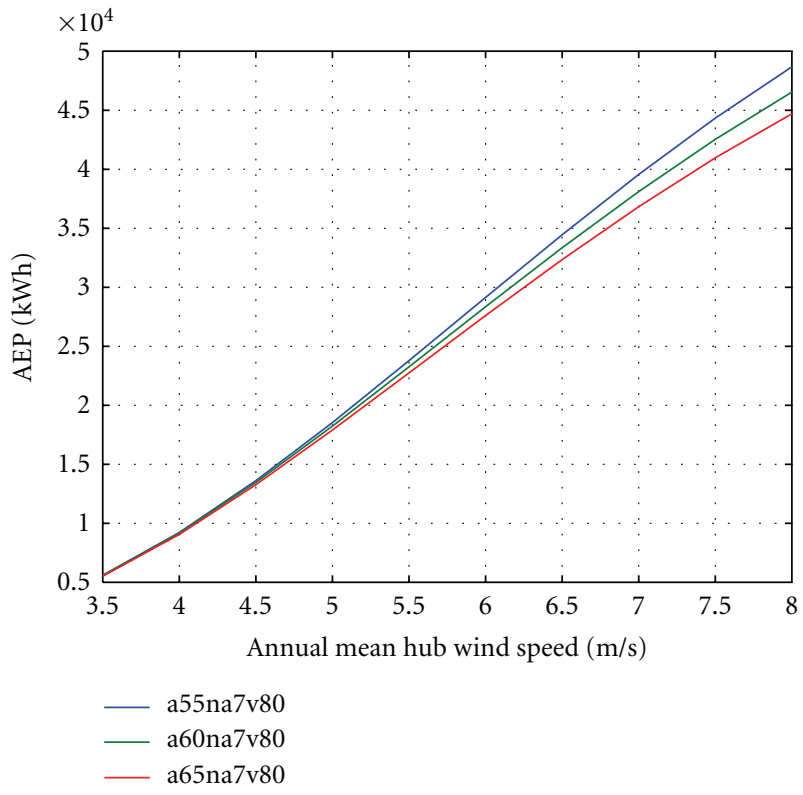

Figure 7: AEP based on $V_{\text {design }}=8 \mathrm{~m} / \mathrm{s}$ and $\lambda_{0}=7$ for AMWS between $3.5-8 \mathrm{~m} / \mathrm{s}$.

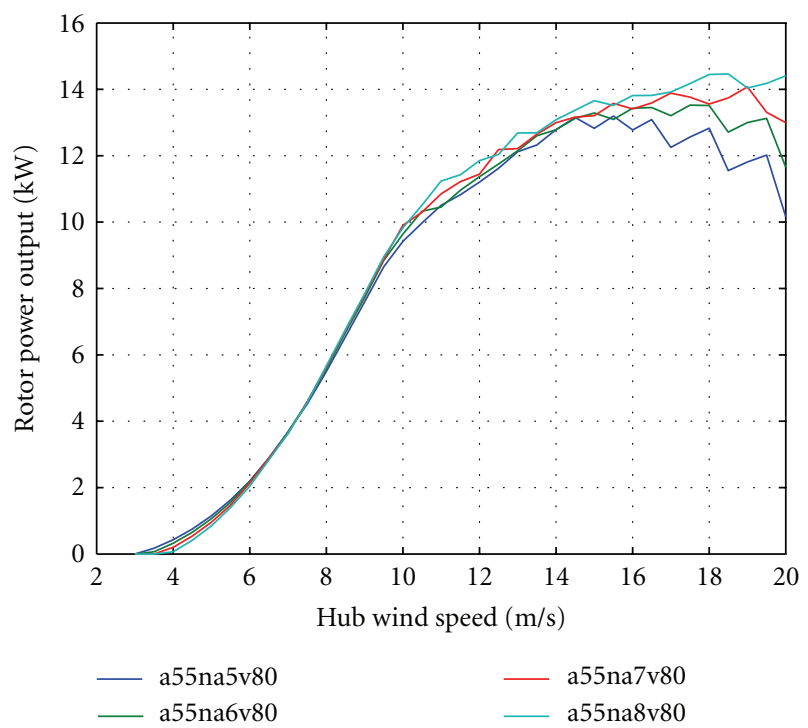

FIGURE 8: Rotor power output based on $V_{\text {design }}=8 \mathrm{~m} / \mathrm{s}$ and $\alpha_{0}=$ $5.5^{\circ}$.

5.3. With Different Design Tip Speed Ratio. Now let us consider different design tip speed ratio by keeping design wind speed $V_{\text {design }}=8 \mathrm{~m} / \mathrm{s}$ and design attack angle $\alpha_{0}=5.5^{\circ}$. Figure 8 depicts the rotor power performances of this set of design cases.

Similar to Figure 2, in Figure 8, for the expression “a***na* $\mathrm{v}^{* *}$ ", "a" represents attack angle, a55 means $\alpha_{0}=$ $5.5^{\circ}$; "na" represents design tip speed ratio, na7 means $\lambda_{0}=$ 7 ; "v" represents design wind speed, v80 means $V_{\text {design }}=$ $8.0 \mathrm{~m} / \mathrm{s}$.

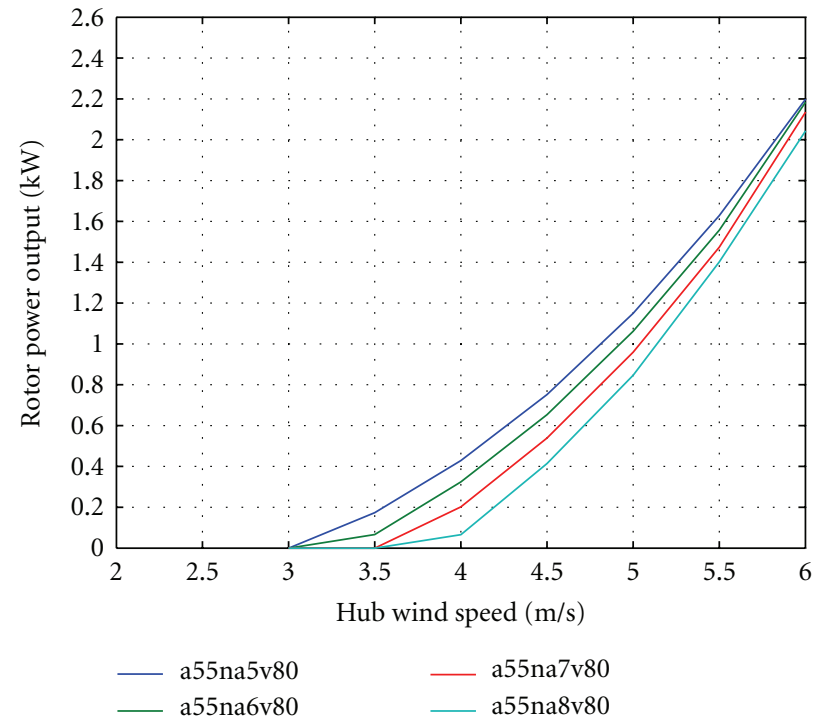

FIGURE 9: Rotor power output based on $V_{\text {design }}=8 \mathrm{~m} / \mathrm{s}$ and $\alpha_{0}=$ $5.5^{\circ}$ for wind speed between $3-6 \mathrm{~m} / \mathrm{s}$.

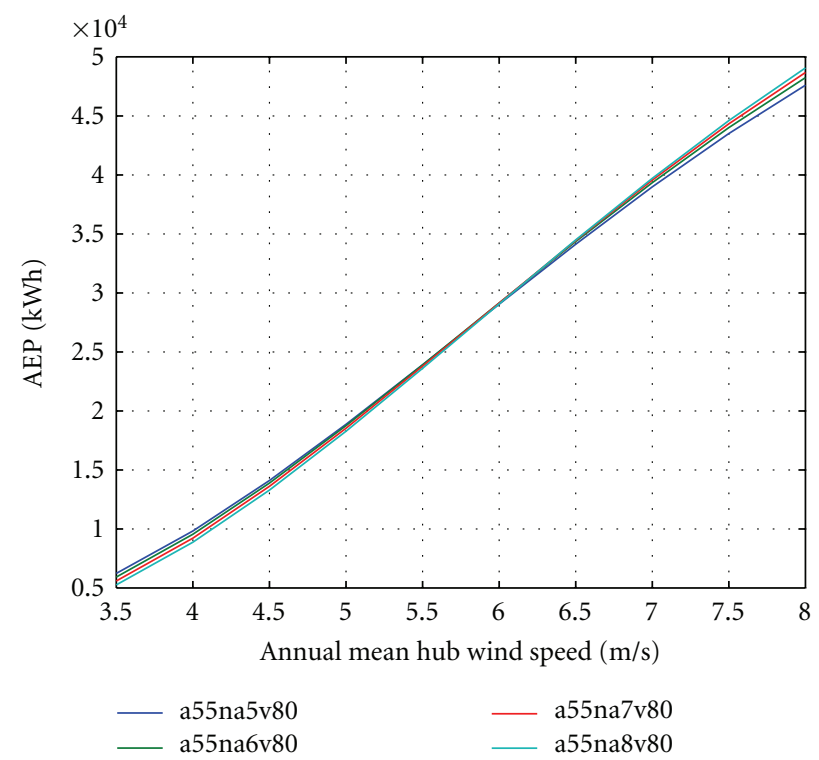

FIGURE 10: AEP based on $V_{\text {design }}=8 \mathrm{~m} / \mathrm{s}$ and $\alpha_{0}=5.5^{\circ}$ for AMWS between $3.5-8 \mathrm{~m} / \mathrm{s}$.

Figure 8 demonstrates that with higher design tip speed ratio, the rotor exhibits higher power output when the wind speed is higher than about $7 \mathrm{~m} / \mathrm{s}$; however, the rotor exhibits lower power output when the wind speed is lower than about $7 \mathrm{~m} / \mathrm{s}$. Figure 9 enlarges the figure section for the wind speed between $3-6 \mathrm{~m} / \mathrm{s}$. This figure also shows that higher design tip speed ratio means higher cut-in wind speed.

Figure 10 shows the annual energy production (AEP) for annual mean wind speed (AMWS) from $3.5 \mathrm{~m} / \mathrm{s}$ to $8 \mathrm{~m} / \mathrm{s}$, and Figure 11 enlarges the figure section for AMWS between 3.5$7.0 \mathrm{~m} / \mathrm{s}$. 


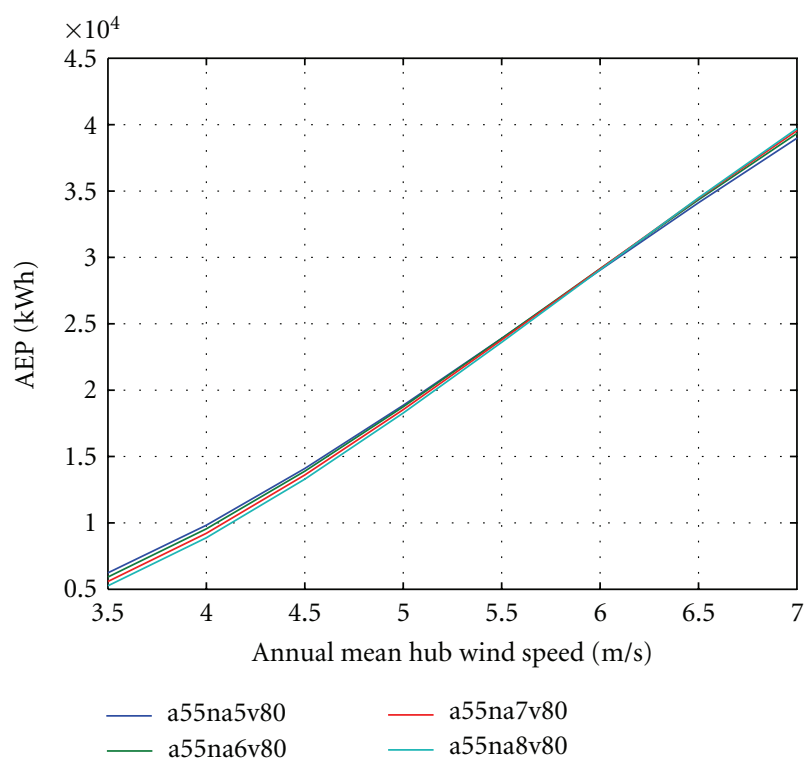

Figure 11: AEP based on $V_{\text {design }}=8 \mathrm{~m} / \mathrm{s}$ and $\alpha_{0}=5.5^{\circ}$ for AMWS between $3.5-7.0 \mathrm{~m} / \mathrm{s}$.

Figures 10 and 11 reveal that with higher than roughly $6.35 \mathrm{~m} / \mathrm{s}$ AMWS, higher tip speed ratio exhibits higher AEP. However when the AWMS is less than approximately $6.35 \mathrm{~m} / \mathrm{s}$, higher tip speed ratio exhibits lower AEP. At sites in rural areas in the UK, the AMWS is unlikely to be above $6.35 \mathrm{~m} / \mathrm{s}$ at the hub height for a $10 \mathrm{~kW}$ wind turbine. Therefore, a low tip speed ratio should be considered, such as $\lambda_{0}=5-6$ if the AMWS is between $5 \mathrm{~m} / \mathrm{s}$ and $6 \mathrm{~m} / \mathrm{s}$.

\section{Conclusions and Recommendations}

Through case studies, this paper demonstrates a practical selection method for determining the optimum blade design parameters, that is, design wind speed, tip speed ratio, and attack angle, for a fixed-pitch fixed-speed small wind turbine with a given baseline wind turbine and its blade airfoil. The conclusions and recommendations are as follows:

(1) the best design attack angle for fixed-pitch fixedspeed wind turbine is not necessarily the angle with the maximum $C_{l} / C_{d}$. For the design case, the best attack angle is $\alpha_{0}=5.5^{\circ}$ even though the maximum $C_{l} / C_{d}$ appears at the attack angle $\alpha_{0}=6.0^{\circ} ;$

(2) the design wind speed should be considered carefully for a baseline wind turbine with fixed-pitch fixedspeed control strategy. If the design wind speed is too low, the wind turbine rotor cannot achieve expected rotor power output for the whole operating wind speed range. If the design wind speed is too high, the wind turbine rotor exceeds the rated power too much. For the design case, design wind speed $V_{\text {design }}=8 \mathrm{~m} / \mathrm{s}$ exhibits best performance for any site with annual mean speed above $4.5 \mathrm{~m} / \mathrm{s}$;

(3) in terms of design tip speed ratio for a fixed-pitch fixed-speed wind turbine, low tip speed ratio is recommended when the annual mean wind speed is low. However, high tip speed ratio yields more energy when the annual mean wind speed is high. For the design case, $\lambda_{0}=5-6$ should be considered if the annual mean wind speed is between $5 \mathrm{~m} / \mathrm{s}$ and $6 \mathrm{~m} / \mathrm{s}$;

(4) this method can be used for any practice of fixedpitch fixed-speed wind turbine blade design;

(5) this method can be used for wind turbine blade refurbishment. Due to use of the existing gearbox and generator, the rotor speed is fixed, and there is very limited space to change the rotor diameter and blade tip speed. Therefore, when selecting the design attack angle, design wind speed and design tip speed ratio according to the findings of this paper, the above constraint should be considered.

\section{References}

[1] M. Jureczko, M. Pawlak, and A. Męzyk, "Optimisation of wind turbine blades," Journal of Materials Processing Technology, vol. 167, no. 2-3, pp. 463-471, 2005.

[2] F. D. Bianchi, H. D. Battista, and R. J. Mantz, Wind Turbine Control Systems: Principles, Modelling and Gain Scheduling Design, Springer, London, UK, 2007.

[3] P. G. Pierce and K. G. Migliore, "Maximizing energy capture of fixed-pitch variable-speed wind turbines," Tech. Rep. NREL/CP-500-27551, 2000.

[4] S. Li and T. A. Haskew, "Simulation study of fixed speed wind energy conversion system and compensation using PSpice," in Proceedings of the International Conference on Power and Energy Systems (PES '07), vol. 539, January 2007.

[5] D. Saheb-Koussa, M. Haddadi, M. Belhamel, S. Hadji, and S. Nouredine, "Modeling and simulation of the fixed-speed WECS (wind energy conversion system): application to the Algerian Sahara area," Energy, vol. 35, no. 10, pp. 4116-4125, 2010.

[6] G. C. Venkatesh and S. V. Kulkarni, "Energy yield of passive stall regulated fixed speed wind turbine with optimal rotor speed," Electric Power Systems Research, vol. 76, no. 12, pp. 1019-1026, 2006.

[7] J. Zhang, A. Dyśko, J. O’Reilly, and W. E. Leithead, "Modelling and performance of fixed-speed induction generators in power system oscillation stability studies," Electric Power Systems Research, vol. 78, no. 8, pp. 1416-1424, 2008.

[8] J. F. Manwell, J. G. McGowan, and A. L. Rogers, Wind Energy Explained: Theory, Design and Application, Wiley, New York, NY, USA, 2nd edition, 2009.

[9] A. Vardar and B. Eker, "Principle of rotor design for horizontal axis wind turbines," Journal of Applied Sciences, vol. 6, no. 7, pp. 1527-1533, 2006.

[10] C. Bak, "Sensitivity of key parameters in aerodynamic wind turbine rotor design on power and energy performance," Journal of Physics, vol. 75, no. 1, Article ID 012008, 2007.

[11] C. Thumthae and T. Chitsomboon, "Optimal angle of attack for untwisted blade wind turbine," Renewable Energy, vol. 34, no. 5, pp. 1279-1284, 2009.

[12] M. O. L. Hansena, J. N. Sorensena, S. Voutsinasb, and H. A. Madsenc, "State of the art in wind turbine aerodynamics and 
aeroelasticity," Progress in Aerospace Sciences, vol. 42, pp. 285330, 2006.

[13] N. S. Çetin, M. A. Yurdusev, R. Ata, and A. Özdemir, "Assessment of optimum tip speed ratio of wind turbines," Mathematical and Computational Applications, vol. 10, no. 1, pp. 147-154, 2005.

[14] M. A. Yurdusev, R. Ata, and N. S. Çetin, "Assessment of optimum tip speed ratio in wind turbines using artificial neural networks," Energy, vol. 31, no. 12, pp. 2153-2161, 2006.

[15] E. A. Bossanyi, "GH bladed theory manual," Tech. Rep. 282/BR/009, 2008.

[16] E. Hau, Wind Turbines: Fundamentals, Technologies, Application, Economics, Springer, London, UK, 2nd edition, 2006.

[17] R. K. Singh, M. R. Ahmed, M. A. Zullah, and Y. H. Lee, "Design of a Low Reynolds number airfoil for small horizontal axis wind turbines," Renewable Energy, vol. 42, pp. 66-76, 2011.

[18] M. Drela, "XFOIL: an analysis and design system for Low Reynolds number airfoils," in Proceedings of the Conference on Low Reynolds Number Airfoil Aerodynamics, University of Notre Dame, June 1989. 

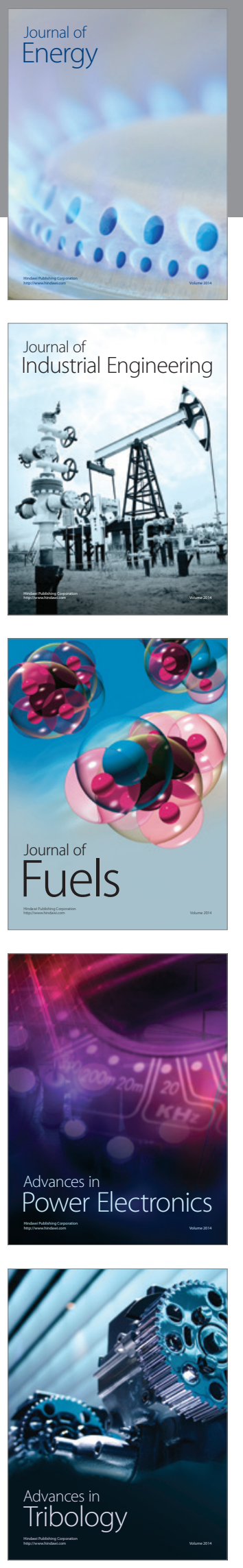
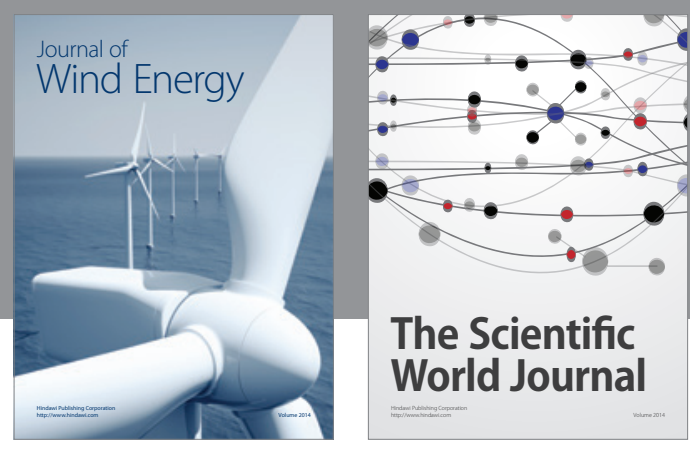

The Scientific World Journal

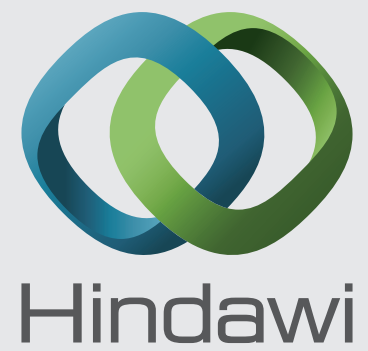

Submit your manuscripts at http://www.hindawi.com
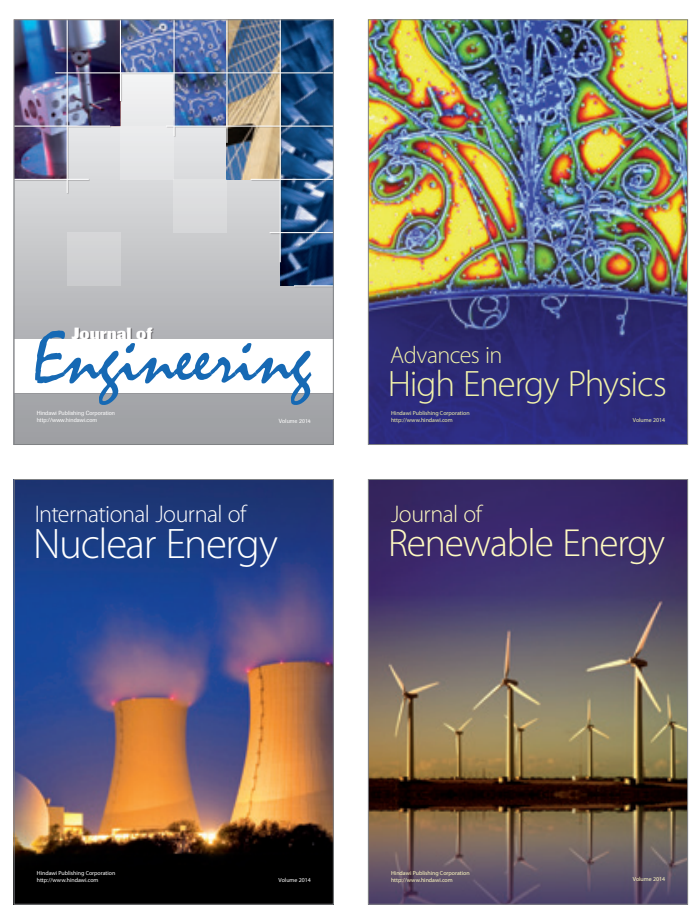

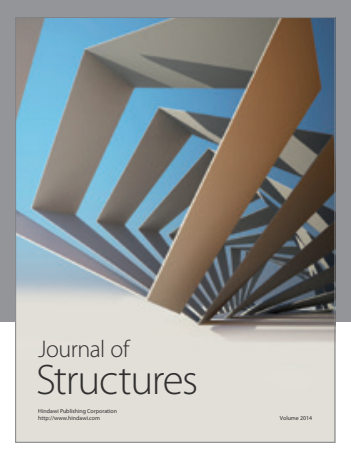

Rotating
Mechinery
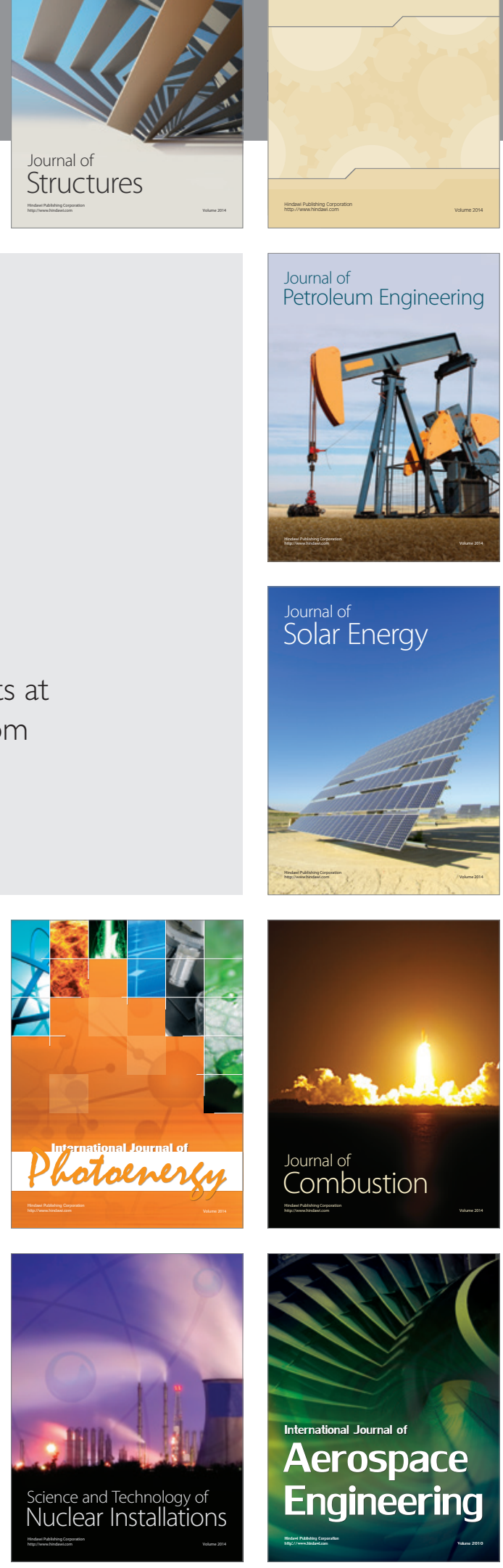